\title{
Oceanobacillus chironomi sp. nov., a halotolerant and facultatively alkaliphilic species isolated from a chironomid egg mass
}

\author{
Dina Raats and Malka Halpern
}

Correspondence

Malka Halpern

mhalpern@research.haifa.ac.il
Department of Biology, Faculty of Science and Science Education, University of Haifa, Oranim, Tivon 36006, Israel

\begin{abstract}
Chironomids (Diptera; Chironomidae) are the most abundant insects in freshwater aquatic habitats. Females of the genus Chironomus lay egg masses containing hundreds of eggs embedded in a gelatinous matrix. A bacterial strain, designated $\mathrm{T}^{3} 944 \mathrm{D}^{\top}$, was isolated from a chironomid egg mass sampled from a waste-stabilization pond in northern Israel and was found to be Gram-positive, motile by peritrichous flagella, endospore-forming, halotolerant and facultatively alkaliphilic.

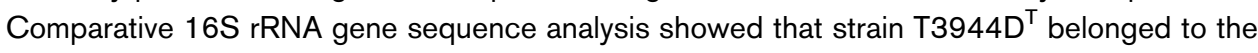
genus Oceanobacillus, exhibiting the highest levels of similarity with the sequences of Oceanobacillus oncorhynchi subsp. incaldanensis DSM $16557^{\top}(94.9 \%)$, Oceanobacillus oncorhynchi subsp. oncorhynchi JCM $12661^{\top}(94.8 \%)$, Oceanobacillus iheyensis JCM $11309^{\top}$ (94.7\%) and Oceanobacillus picturae LMG 19416 (94.5\%). Strain T3944D ${ }^{\top}$ grew optimally at $1-3 \% \mathrm{NaCl}, \mathrm{pH} 8.5$ and $37^{\circ} \mathrm{C}$. The major cellular fatty acids were anteiso- $\mathrm{C}_{15: 0}(60.0 \%)$ and anteiso- $\mathrm{C}_{17: 0}(12.9 \%)$ and the DNA G $+\mathrm{C}$ content was $38.1 \mathrm{~mol} \%$. On the basis of its phenotypic properties and phylogenetic distinctiveness, strain $\mathrm{T3}_{3} 44 \mathrm{D}^{\top}$ represents a novel species in the genus Oceanobacillus, for which the name Oceanobacillus chironomi sp. nov. is proposed. The type strain is T3944D ${ }^{\top}$ (= LMG $23627^{\top}=$ DSM $18262^{\top}$ ).
\end{abstract}

The genus Oceanobacillus was first described by Lu et al. (2001, 2002) and at the time of writing comprises three species: O. iheyensis (Lu et al., 2001), whose entire genome sequence has been determined and is now available (Takami et al., 2002), O. oncorhynchi (Yumoto et al., 2005) and $O$. picturae, which was recently transferred from the genus Virgibacillus (Lee et al., 2006). All of the species belonging to this genus are halophilic or halotolerant and alkaliphilic or alkalitolerant.

Chironomids (Diptera; Chironomidae) are the most abundant insects in freshwater aquatic habitats. Females of the genus Chironomus lay egg masses at the water's edge. Each egg mass contains hundreds of eggs embedded in a thick, gelatinous matrix. Chironomid egg masses harbour Vibrio cholerae and provide a natural reservoir for this bacterium (Broza \& Halpern, 2001; Halpern et al., 2003, 2004, 2006). All Vibrio cholerae isolates have the capacity to degrade chironomid egg masses and prevent the eggs from hatching (Halpern et al., 2003, 2004, 2006). Strain T3944D ${ }^{\mathrm{T}}$ was isolated in the course of screening of the microbial population of chironomid egg masses (Halpern et al., 2007). The egg masses were sampled in mid-September 2004 from

The GenBank/EMBL/DDBJ accession number for the 16S rRNA gene sequence of strain T3944D ${ }^{\top}$ is DQ298074. the Tivon waste-stabilization pond near Haifa (northern Israel), using Styrofoam boards as artificial oviposition sites for the adult female chironomids. The egg masses were thoroughly washed and then cultured directly on three bacteriological media, thiosulphate-citrate-bile salts agar (selective for Vibrio cholerae), LB agar and MacConkey agar. Strain T3944D ${ }^{\mathrm{T}}$ was one of the colonies that was randomly picked and streaked from the LB agar. More than $10^{2}$ faecal coliforms $\mathrm{ml}^{-1}$ were counted in the water samples from the Tivon waste-stabilization pond (Halpern et al., 2004), but no faecal coliforms were isolated from the egg mass even though MacConkey agar (selective for Escherichia coli) was used. This confirmed that the egg masses had been rinsed properly and that strain $\mathrm{T} 3944 \mathrm{D}^{\mathrm{T}}$ and the other isolates had been tightly attached to the egg mass.

Diverse types of bacteria have been isolated from the egg masses and characterized (Halpern et al., 2007). One of these isolates, a Gram-positive, halotolerant, facultatively alkaliphilic, spore-forming, motile bacillus, designated strain T3944 $\mathrm{D}^{\mathrm{T}}$, is described here. Its exact taxonomic position was determined by using a polyphasic approach that included phenotypic analysis and a phylogenetic investigation based on 16S rRNA gene sequences.

For electron microscopy, bacteria from LB agar were suspended in saline. The samples were attached to a 


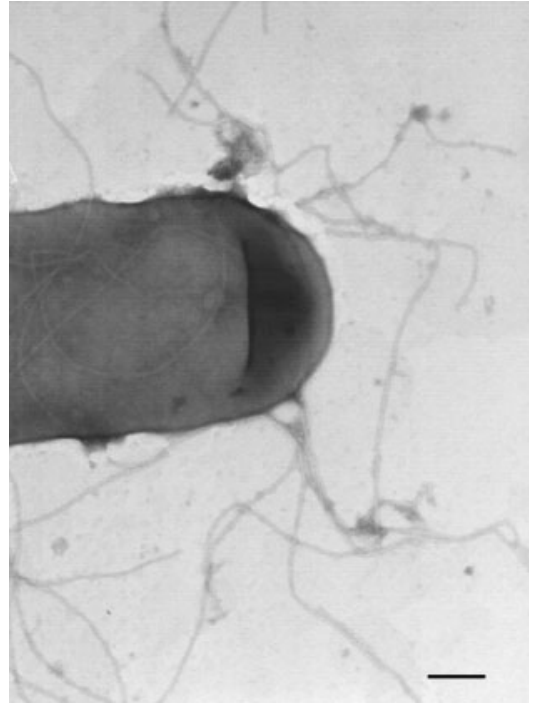

Fig. 1. Electron micrograph of a negatively stained cell of strain T3944D', showing the peritrichous flagellation of the rod. Bar, $200 \mathrm{~nm}$.

carbon-coated grid, stained with $2 \%$ uranyl acetate and then photographed under a JEM-1200EX electron microscope (JEOL). Electron microscopy showed that the cells were peritrichously flagellated rods $(0.8-1.0 \times 1.3-3.0 \mu \mathrm{m})$ (Fig. 1).

The 16S rRNA gene was analysed to determine the phylogenetic position of strain $\mathrm{T} 3944 \mathrm{D}^{\mathrm{T}}$. Universal bacterial primers $8 \mathrm{f}$ and 1512 r, based on E. coli positions, were used to amplify internal fragments of the $16 \mathrm{~S}$ rRNA gene, according to Felske et al. (1997). The amplified PCR product (approx. $1.5 \mathrm{~kb}$ ) was purified with a Wizard PCR product-purification kit (Promega). Purified PCR products were sequenced directly by the dideoxynucleotide chain-termination method, using a DNA sequencer (ABI PRIZM 3100) with
BigDye terminator reagents (Applied Biosystems), according to the instructions of the manufacturer (at Technion Medical School, Haifa, Israel). Sequencing was performed using primers 8f (5'-CACGGATCCAGACTTTGATYMTGGCTCAG-3'), 519f ( $5^{\prime}$-CAGCMGCCGCGGTAATWC$\left.3^{\prime}\right)$, 534r (5'-ATTACCGCGGCTGCTGG-3') and $968 \mathrm{f}$ $\left(5^{\prime}\right.$-AACGCGAAGAACCTTAC-3'). This resulted in data relating to approximately $1471 \mathrm{bp}$. To identify the closest relatives, the newly determined sequence was compared with those available in GenBank (http://www.ebi.ac.uk) by using the WU BLAST program (Washington University Basic Local Alignment Search Tool, version 2.0). Sequence alignment was performed using the CLUSTAL $\mathrm{W}$ program, and the phylogenetic tree was generated using the neighbour-joining method in the MEGA3 software (Kumar et al., 2004). Bootstrap values (from 1000 replicates) greater than $50 \%$ are shown at the branch points in the tree presented in Fig. 2.

The 1471-base sequence of the 16S rRNA gene of strain

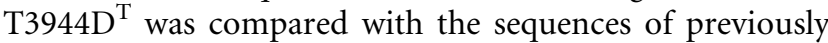
reported strains. Strain T3944D ${ }^{\mathrm{T}}$ showed the highest levels of similarity with O. oncorhynchi subsp. incaldanensis DSM $16557^{\mathrm{T}}(94.9 \%)$, O. oncorhynchi subsp. oncorhynchi JCM $12661^{\mathrm{T}}(94.8 \%)$, O. iheyensis JCM $11309^{\mathrm{T}}(94.7 \%)$ and $O$. picturae LMG 19416 (94.5\%). The similarities between

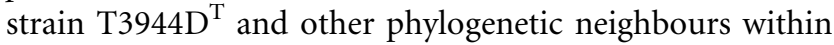
the genera Virgibacillus and Bacillus were less than $94.5 \%$ (Fig. 2).

For the phenotypic characterization, LB agar was used as the basal medium, except for the determination of the $\mathrm{pH}$ range, for which peptone-yeast extract medium supplemented with $1 \% \mathrm{NaCl}$ was used (according to $\mathrm{Lu}$ et al., 2001). Salt tolerance was determined at $37^{\circ} \mathrm{C}$ on $\mathrm{LB}$ agar containing varying concentrations of $\mathrm{NaCl}$. Growth at various temperatures $(4,6,10,11,12,15,25,30,32,35,37,39$, $40,44,46,47,48$ and $50^{\circ} \mathrm{C}$ ) was measured on LB agar (pH 8.5) supplemented with $1 \% \mathrm{NaCl}$. Growth under anaerobic conditions was determined after incubation of the novel strain, in an anaerobic chamber, on LB agar

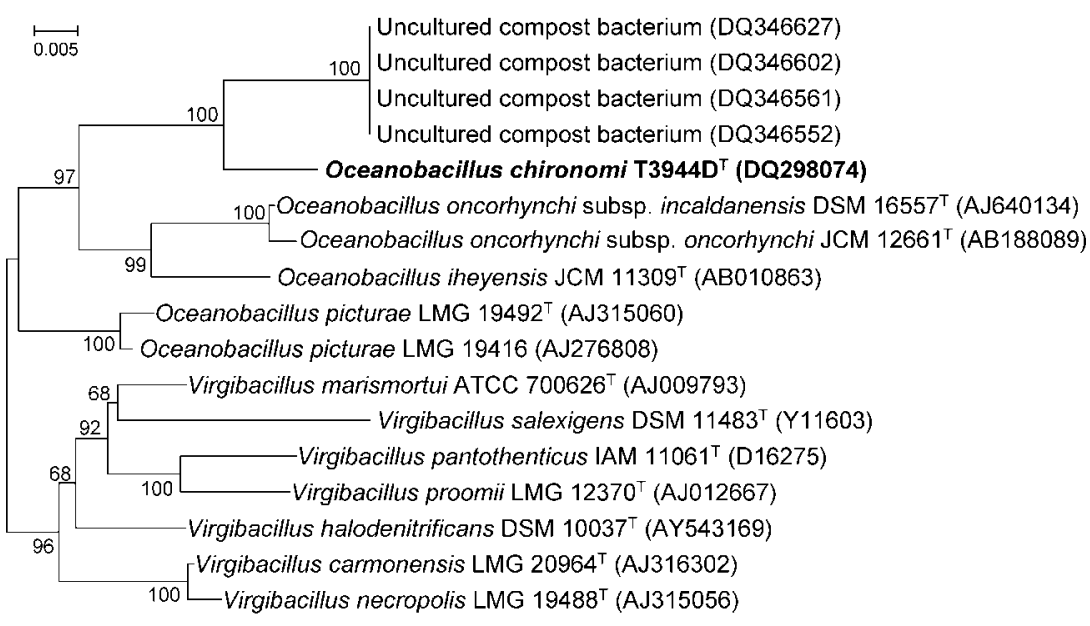

Fig. 2. Neighbour-joining tree (obtained with MEGA3, based on an alignment from CLUSTAL $W$ ), based on 16S rRNA gene sequence data, showing the phylogenetic position of

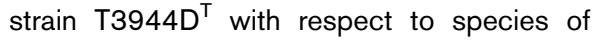
the genus Oceanobacillus and other related taxa. Percentage bootstrap values are indicated. Bar, 0.005 accumulated changes per nucleotide. 
containing $1 \% \mathrm{NaCl}(\mathrm{pH} 8.5)$ and on LB agar supplemented with nitrate. Strain $\mathrm{T} 3944 \mathrm{D}^{\mathrm{T}}$ showed optimal growth at $1-3 \% \mathrm{NaCl}, \mathrm{pH} 8.5$ and $37^{\circ} \mathrm{C}$ (Table 1).

Biochemical tests were performed by using the API $20 \mathrm{E}$ system (micromethod tests for the identification of Gramnegative rods; bioMérieux). Carbon assimilation was analysed using Biolog GP microwell plates according to the manufacturer's instructions (release 3.50, version DE; Biolog). The plates were incubated for $48 \mathrm{~h}$ at $37^{\circ} \mathrm{C}$. Wells that changed to purple were scored as being positive for metabolic activity. The sensitivity of strain $\mathrm{T}_{3} 944 \mathrm{D}^{\mathrm{T}}$ to antibiotics was tested by using LB agar and Sensi-Discs (BBL) after incubation for $48 \mathrm{~h}$.

For analysis of the cellular fatty acids, cells were cultured on tryptic soy agar at $28^{\circ} \mathrm{C}$ before extraction of the fatty acids. The microbial fatty acid profile was analysed using the MIDI/Hewlett Packard microbial identification system (Analytical Services), which uses GC profiles of fatty acid methyl esters. The measurable fatty acid components of strain $\mathrm{T} 3944 \mathrm{D}^{\mathrm{T}}$ were as follows: iso- $\mathrm{C}_{14: 0}$ $(5.03 \%), \mathrm{C}_{14: 0}(2.39 \%)$, iso- $\mathrm{C}_{15: 0}(6.08 \%)$, anteiso- $\mathrm{C}_{15: 0}$ $(59.97 \%)$, iso- $\mathrm{C}_{16: 0}(5.92 \%), \mathrm{C}_{16: 0}(7.72 \%)$ and anteiso$\mathrm{C}_{17: 0}(12.89 \%)$.
For determination of the DNA G $+\mathrm{C}$ content, genomic DNA of strain $\mathrm{T} 3944 \mathrm{D}^{\mathrm{T}}$ was prepared according to a modified version of the procedure of Wilson (1987). The $\mathrm{G}+\mathrm{C}$ content of the DNA sample was determined in three independent analyses using the HPLC technique (Mesbah et al., 1989) and was performed by the BCCM/LMG Bacteria Collection Identification Service (Laboratory of Microbiology, Ghent University, Ghent, Belgium). The

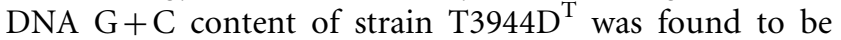
$38.1 \mathrm{~mol} \%$.

Strain $\mathrm{T} 3944 \mathrm{D}^{\mathrm{T}}$ was isolated from chironomid egg masses, along with Vibrio cholerae and other culturable bacterial populations that inhabit this environment (Halpern et al., 2007). The eggs are embedded in a gelatinous matrix and,

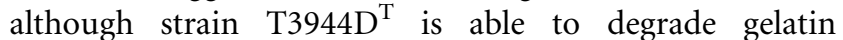
(Table 1), unlike all Vibrio cholerae isolates from the same niche (Halpern et al., 2003, 2006), it does not degrade the egg mass.

The genus Oceanobacillus was created by Lu et al. (2001, 2002) and at the time of writing contains three species, which were isolated from quite different environments: (i) O. iheyensis, which is of marine origin; (ii) O. oncorhynchi subsp. oncorhynchi, O. oncorhynchi subsp. incaldanensis and

\section{Table 1. Differential characteristics of strain T3944D ${ }^{\top}$ and Oceanobacillus species}

Strains: 1, O. chironomi sp. nov. strain $\mathrm{T}^{3} 944 \mathrm{D}^{\mathrm{T}} ; 2$, O. oncorhynchi subsp. incaldanensis DSM $16557^{\mathrm{T}}$; 3, O. oncorhynchi subsp. oncorhynchi JCM $12661^{\mathrm{T}} ; 4$, O. iheyensis JCM $11309^{\mathrm{T}}$; 5, O. picturae LMG $19492^{\mathrm{T}}$. Data were obtained from Lu et al. (2001), Heyrman et al. (2003), Yumoto et al. (2005), Lee et al. (2006), Romano et al. (2006) and this study. ND, Not determined; W, weakly positive reaction.

\begin{tabular}{|c|c|c|c|c|c|}
\hline Characteristic & 1 & 2 & 3 & 4 & 5 \\
\hline Cell size $(\mu \mathrm{m})$ & $0.8-1.0 \times 1.3-3.0$ & $0.5-0.8 \times 1.2-2.0$ & $0.4-0.6 \times 1.1-1.4$ & $0.6-0.8 \times 2.5-3.5$ & $0.5-0.7 \times 2.0-6.0$ \\
\hline Colony colour & Cream-beige & Cream-beige & White & Cream-white & Cream \\
\hline Anaerobic growth & - & - & + & - & - \\
\hline \multicolumn{6}{|l|}{ Hydrolysis of: } \\
\hline Casein & - & - & - & + & $\mathrm{W}$ \\
\hline Reduction of nitrate to nitrite & + & + & + & - & + \\
\hline Reduction of nitrite to $\mathrm{N}_{2}$ & + & + & - & - & - \\
\hline $\mathrm{NaCl}$ range for growth (\%) & $0-11$ & $5-20$ & $0-22$ & $0-21$ & $0-10$ \\
\hline $\mathrm{NaCl}$ optimum (\%) & $1-3$ & 10 & 3 & 3 & 7 \\
\hline DNA G + C content $(\mathrm{mol} \%)$ & 38.1 & 40.1 & 38.5 & 35.8 & 39.5 \\
\hline $\begin{array}{l}\text { Major cellular fatty acids } \\
(>10 \% \text { of total })^{\star}\end{array}$ & $\begin{array}{l}\text { anteiso-C15:0, } \\
\text { anteiso-C17 }: 0^{a}\end{array}$ & $\begin{array}{l}\text { iso-C14:0, } \\
\text { iso-C15:0, } \\
\text { anteiso-C15: } 0^{b}\end{array}$ & $\begin{array}{c}\text { iso-C15:0, } \\
\text { anteiso-C15:0, } \\
\text { anteiso-C17 }: 0^{b}\end{array}$ & $\begin{array}{l}\text { iso-C14:0, } \\
\text { iso-C15:0, } \\
\text { anteiso-C15:0 }\end{array}$ & $\begin{array}{c}\text { iso-C14:0, } \\
\text { anteiso-C15:0, } \\
\text { anteiso-C17 : } 0^{d}\end{array}$ \\
\hline
\end{tabular}

${ }^{*}$ Growth conditions for fatty acids analysis: $a$, tryptic soy agar, $28{ }^{\circ} \mathrm{C} ; b$, no data available; $c$, marine broth and $10 \%$ moderate halophile medium, $37^{\circ} \mathrm{C}$ (Lu et al., 2001) and tryptic soy agar, $28^{\circ} \mathrm{C}$ (this study); $d$, tryptic soy agar, $30^{\circ} \mathrm{C}$. 
strain $\mathrm{T} 3944 \mathrm{D}^{\mathrm{T}}$, which are of freshwater origin; and (iii) $O$. picturae, which was isolated from a mural painting. The phylogenetic relationships among strain $\mathrm{T} 3944 \mathrm{D}^{\mathrm{T}}$ and related taxa are shown in Fig. 2. The comparative $16 \mathrm{~S}$ rRNA gene sequence analysis showed that the novel isolate is phylogenetically most closely related to Oceanobacillus species (94.5-94.9\% sequence similarity). Strain T3944D ${ }^{\mathrm{T}}$ shared the main characteristics with Oceanobacillus species, for example, they were positive for catalase and oxidase, they were motile rods (having peritrichous flagella), they produced endospores and they were halotolerant (except for O. oncorhynchi subsp. incaldanensis DSM $16557^{\mathrm{T}}$, which is halophilic and also does not produce endospores) (Table 1). The DNA G $+\mathrm{C}$ content of strain T3944D ${ }^{\mathrm{T}}$ (38.1 mol\%) is within the range for Oceanobacillus species $(35.8-40.1 \mathrm{~mol} \%)$ and its major cellular fatty acid is anteiso$\mathrm{C}_{15: 0}$ (Table 1).

However, strain $\mathrm{T} 3944 \mathrm{D}^{\mathrm{T}}$ possesses a unique combination of the properties that characterize the members of the genus Oceanobacillus. It is halotolerant and is a facultatively alkaliphilic obligate aerobe (Table 1). It hydrolyses gelatin, is able to reduce nitrite to $\mathrm{N}_{2}$ and has a unique fatty acid profile [including anteiso- $\mathrm{C}_{15: 0}(60.0 \%)$ and anteiso- $\mathrm{C}_{17: 0}$ $(12.9 \%)$ ] (Table 1). It grows at $46^{\circ} \mathrm{C}$, which is a higher growth temperature than that of any Oceanobacillus species (Table 1). In the National Center for Biotechnology Information database (http://www.ncbi.nlm.nih.gov/blast/), four sequences (GenBank accession numbers DQ346552, DQ346561, DQ346602 and DQ346627) of uncultured and undescribed compost bacteria showed $98.6 \% 16 \mathrm{~S}$ rRNA gene sequence similarity with respect to strain $\mathrm{T} 3944 \mathrm{D}^{\mathrm{T}}$. These uncultured strains, which were identified during a clone library study of the bacterial diversity of compost from Korea, probably fall within the lineage of the novel species proposed here (Fig. 2).

On the basis of the phenotypic characterization and the phylogenetic analysis, strain $\mathrm{T} 3944 \mathrm{D}^{\mathrm{T}}$ should be classified as a novel species, for which the name Oceanobacillus chironomi sp. nov. is proposed.

\section{Description of Oceanobacillus chironomi sp. nov.}

Oceanobacillus chironomi [chi.ro'no.mi. N.L. gen. n. chironomi of Chironomus, named after the non-biting midge insect of the genus Chironomus (Chironomidae: Diptera) from which the type strain was isolated].

Cells are Gram-positive, peritrichously flagellated rods $(0.8-1.0 \times 1.3-3.0 \mu \mathrm{m})$ (Fig. 1) that sometimes form chains. Cells produce ellipsoidal spores terminally or subterminally positioned within swollen sporangia. Colonies are circular and cream-beige in colour. Colony colour darkens from the centre as the culture ages. Obligately aerobic and does not ferment carbohydrates. Facultatively alkaliphilic. Grows at pH 6.5-10, with optimal growth at $\mathrm{pH}$ 8.5. Halotolerant and grows with $0-11 \%$
$\mathrm{NaCl}$, with optimal growth at $1-3 \% \mathrm{NaCl}$. Catalase- and oxidase-positive. Growth occurs at $12-46^{\circ} \mathrm{C}$, with optimum growth at $37^{\circ} \mathrm{C}$. Negative for indole production, ONPG hydrolysis and deamination of phenylalanine. Cells are resistant to tetracycline but susceptible to penicillin G, ampicillin, vancomycin, streptomycin, chloramphenicol, bacitracin, novobiocin, gentamicin, neomycin and kanamycin. The following substrates are assimilated in the Biolog test: dextrin, $N$-acetyl-D-glucosamine, D-fructose, D-galactose, $\alpha$-D-glucose, $\alpha$-D-lactose, maltose, maltotriose, D-mannose, D-melibiose, D-ribose, $\alpha$-ketoglutaric acid, $\alpha$ ketovaleric acid, L-alaninamide, 2,3-butanediol, glycerol and adenosine. Cellular fatty acids are iso- $\mathrm{C}_{14: 0}$ $(5.0 \%), \mathrm{C}_{14: 0}(2.4 \%)$, iso- $\mathrm{C}_{15: 0}(6.1 \%)$, anteiso- $\mathrm{C}_{15: 0}$ $(60.0 \%)$, iso- $\mathrm{C}_{16: 0}(6.0 \%), \mathrm{C}_{16: 0}(7.7 \%)$ and anteiso- $\mathrm{C}_{17: 0}$ $(12.9 \%)$.

The DNA G + C content of the type strain is $38.1 \mathrm{~mol} \%$. The type strain, $\mathrm{T}_{3944 \mathrm{D}^{\mathrm{T}}}\left(=\mathrm{LMG} 23627^{\mathrm{T}}=\mathrm{DSM} 18262^{\mathrm{T}}\right)$, was isolated from a chironomid egg mass sampled from a wastestabilization pond in northern Israel.

\section{References}

Broza, M. \& Halpern, M. (2001). Pathogen reservoirs. Chironomid egg masses and Vibrio cholerae. Nature 412, 40.

Felske, A., Rheims, H., Wolterink, A., Stackebrandt, E. \& Akkermans, A. D. L. (1997). Ribosome analysis reveals prominent activity of an uncultured member of the class Actinobacteria in grassland soils. Microbiology 143, 2983-2989.

Halpern, M., Gancz, H., Broza, M. \& Kashi, Y. (2003). Vibrio cholerae hemagglutinin/protease degrades chironomid egg masses. Appl Environ Microbiol 69, 4200-4204.

Halpern, M., Broza, Y. B., Mittler, S., Arakawa, E. \& Broza, M. (2004). Chironomid egg masses as a natural reservoir of Vibrio cholerae nonO1 and non-O139 in freshwater habitats. Microb Ecol 47, 341-349.

Halpern, M., Raats, D., Lavion, R. \& Mittler, S. (2006). Dependent population dynamics between chironomids (non-biting midges) and Vibrio cholerae. FEMS Microbiol Ecol 55, 98-104.

Halpern, M., Landsberg, O., Raats, D. \& Rosenberg, E. (2007). Culturable and VBNC Vibrio cholerae; interactions with chironomid egg masses and their bacterial population. Microb Ecol (in press). doi:10.1007/s00248-006-9094-0

Heyrman, J., Logan, N. A., Busse, H.-J., Balcaen, A., Lebbe, L., Rodriguez-Diaz, M., Swings, J. \& De Vos, P. (2003). Virgibacillus carmonensis sp. nov., Virgibacillus necropolis sp. nov. and Virgibacillus picturae sp. nov., three novel species isolated from deteriorated mural paintings, transfer of the species of the genus Salibacillus to Virgibacillus, as Virgibacillus marismortui comb. nov. and Virgibacillus salexigens comb. nov., and emended description of the genus Virgibacillus. Int J Syst Evol Microbiol 53, 501-511.

Kumar, S., Tamura, K. \& Nei, M. (2004). MEGA3: integrated software for Molecular Evolutionary Genetics Analysis and sequence alignment. Brief Bioinform 5, 150-163.

Lee, J.-S., Lim, J.-M., Lee, K. C., Lee, J.-C., Park, Y.-H. \& Kim, C.-J. (2006). Virgibacillus koreensis sp. nov., a novel bacterium from a salt field, and transfer of Virgibacillus picturae to the genus Oceanobacillus as Oceanobacillus picturae comb. nov. with emended descriptions. Int J Syst Evol Microbiol 56, 251-257. 
Lu, J., Nogi, Y. \& Takami, H. (2001). Oceanobacillus iheyensis gen. nov., sp. nov., a deep-sea extremely halotolerant and alkaliphilic species isolated from a depth of $1050 \mathrm{~m}$ on the Iheya Ridge. FEMS Microbiol Lett 205, 291-297.

Lu, J., Nogi, Y. \& Takami, H. (2002). Oceanobacillus iheyensis gen. nov., sp. nov. In Validation of the Publication of New Names and New Combinations Previously Effectively Published Outside the IJSEM, List no. 85. Int J Syst Evol Microbiol 52, 685-690.

Mesbah, M., Premachandran, U. \& Whitman, W. B. (1989). Precise measurement of the $\mathrm{G}+\mathrm{C}$ content of deoxyribonucleic acid by high-performance liquid chromatography. Int J Syst Bacteriol 39, 159-167.

Romano, I., Lama, L., Nicolaus, B., Poli, A., Gambacorta, A. \& Giordano, A. (2006). Oceanobacillus oncorhynchi subsp. incaldanensis subsp. nov., an alkalitolerant halophile isolated from an algal mat collected from a sulfurous spring in Campania (Italy), and emended description of Oceanobacillus oncorhynchi. Int J Syst Evol Microbiol 56, 805-810.

Takami, H., Takaki, Y. \& Uchiyama, I. (2002). Genome sequence of Oceanobacillus iheyensis isolated from the Iheya Ridge and its unexpected adaptive capabilities to extreme environments. Nucleic Acids Res 30, 3927-3935.

Wilson, K. (1987). Preparation of genomic DNA from bacteria. In Current Protocols in Molecular Biology, pp. 2.4.1-2.4.5. Edited by F. M. Ausubel, R. Brent, R. E., Kingston, D. D. Moore, J. G. Seidman, J. A. Smith \& K. Struhl. New York: Greene Publishing and Wiley-Interscience.

Yumoto, I., Hirota, K., Nodasaka, Y. \& Nakajima, K. (2005). Oceanobacillus oncorhynchi sp. nov., a halotolerant obligate alkaliphile isolated from the skin of a rainbow trout (Oncorhynchus mykiss), and emended description of the genus Oceanobacillus. Int J Syst Evol Microbiol 55, 1521-1524. 